\title{
Ocular hypertension: a comparative follow-up of black and white patients
}

\author{
ROBERT DAVID, DESIRÉ LIVINGSTON, AND MAURICE H. LUNTZ \\ From the Department of Ophthalmology, University of the Witwatersrand, \\ Johannesburg, South Africa
}

SUMMARY Forty-four eyes in 25 black patients are compared with 92 eyes of 47 white patients in a population with ocular hypertension followed up for 1 to 12 years in a glaucoma clinic. The black patients present at a younger age than the whites and their mean initial intraocular pressure is significantly higher. The fact that more black ocular hypertensives developed glaucoma- 8 eyes $(18.1 \%)$ in the black population as compared with 5 eyes $(5.4 \%)$ in the white population-is attributed to these two differences.

Well documented evidence has been recorded on differences in glaucoma among the races. These differences include: age of onset (Luntz, 1972; Monteiro de Gandt and Maertens, 1973; Clarke, 1973), general incidence (Neumann and Zaubermann, 1965; Mann, 1972; Clarke, 1973), the prevalence of the various types of glaucoma (Luntz, 1973), and the natural history of the disease (Neumann and Zaubermann, 1965; Monteiro de Gandt and Maertens, 1973).

Recently we have reported on the long-term follow-up of patients with ocular hypertension, of whom $10.2 \%$ developed glaucoma during the follow-up period (David et al., 1977). In the present study we are reporting on the differences between white and black patients with ocular hypertension.

\section{Patients and methods}

All the patients attended the glaucoma clinics at the Johannesburg teaching hospitals. The criteria for the diagnosis of ocular hypertension and inclusion in the study are identical to those described in a previous report (David et al., 1977).

Forty-seven white patients (92 eyes) and 25 black patients (44 eyes) with ocular hypertension were followed up for 1 to 12 years. All patients were seen at 2 to 6 month intervals, the intraocular pressure (IOP) was recorded on every visit, and the optic disc was examined. Visual fields were tested with the Goldmann perimeter on every occasion,

Address for reprints: Dr Robert David, Department of Ophthalmology, Medical School, University of the Witwatersrand, Esselen Street, Hillbrow, Johannesburg, South Africa and a Bjerrum tangent screen was performed once or twice a year. Only patients who attended regularly and were followed up for more than 1 year are included in the study.

\section{Results}

The average follow-up time was 47 months for the white patients and 39 months for the blacks.

The mean age of presentation for white patients with ocular hypertension was 65.7 years and for black patients $53 \cdot 1$ years. The mean initial intraocular pressure (mean of 3 readings) and standard deviations for each group are plotted according to each decade of age in Fig. 1. While the highest pressures were measured between 40 and 59 years of age, the number of patients among the white ocular hypertensives increased constantly with age.

Seven black patients (8 eyes) developed glaucoma as compared with 4 ( 5 eyes) from the group of white patients. In 12 eyes pathological cupping of the disc and glaucomatous visual field defects appeared between 12 and 60 months after the initial diagnosis of ocular hypertension, while in only 1 eye the glaucoma developed as late as 79 months after ocular hypertension was diagnosed. Fig. 2 illustrates the relationship between the mean of the initial 3 intraocular pressure readings in each eye (untreated) and the follow-up time for each eye in months, indicating also those eyes which developed glaucoma in both population groups.

The distribution of the mean initial intraocular pressures in the 2 groups and the relationship between this and the development of glaucoma is seen in Table 1. In both white and black patients 
Fig. 1 Variation of mean IOP with age
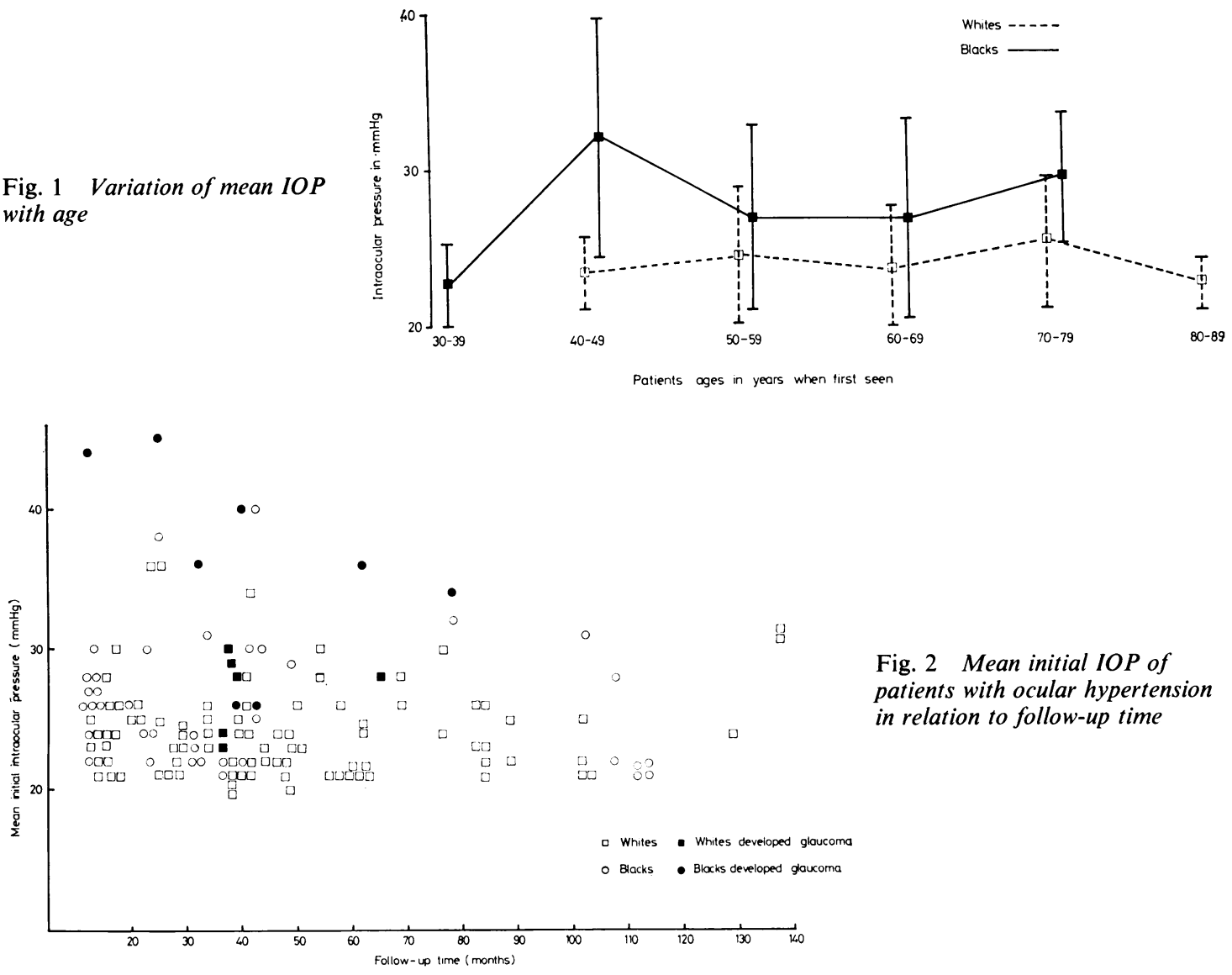

Fig. 2 Mean initial IOP of patients with ocular hypertension in relation to follow-up time the highest incidence of glaucoma was found among patients with intraocular pressure of $31 \mathrm{mmHg}$ or more $(16.6 \%$ in the white ocular hypertensives and $50 \%$ of the blacks).

\section{Discussion}

The incidence of glaucoma developing from ocular hypertension is reported to be between $0.5 \%$ (Armaly, 1969) and 20\% (Walker, 1974). These studies, however, do not specify whether the authors examined patients of different race groups and if any differences between these groups could be noted. In a recent report (Kitazawa $t$ t al., 1977) a $9.3 \%$ incidence of glaucoma from ocular hypertension is reported in a group of patients from Japan.

Our study highlights several differences between black and white patients with ocular hypertension.

(1) The height of the mean intraocular pressure. In black patients 29 eyes $(65.9 \%)$ presented with intraocular pressure higher than $26 \mathrm{mmHg}$ as compared with 24 eyes $(26 \%)$ among the white patients. In both groups the risk of glaucoma was directly related to the initial intraocular pressure

Table 1 Relationship between the level of mean initial intraocular pressure (IOP) and the development of glaucoma from ocular hypertension in the 2 population groups

\begin{tabular}{|c|c|c|c|c|c|c|c|c|c|c|c|c|}
\hline \multirow{2}{*}{$\begin{array}{r}I O P \\
\text { Patients }\end{array}$} & \multicolumn{3}{|c|}{21 to $25 \mathrm{mmHg}$} & \multicolumn{3}{|c|}{26 to $30 \mathrm{~mm} \mathrm{Hg}$} & \multicolumn{3}{|c|}{$31 \mathrm{mmHg}$} & \multicolumn{3}{|l|}{ Total } \\
\hline & Total & Glaucoma & $\%$ & Total & Glaucoma & $\%$ & Total & Glaucoma & $\%$ & Total & Glaucoma & $\%$ \\
\hline White & 68 & 2 & $2 \cdot 9$ & 18 & 2 & $11 \cdot 1$ & 6 & 1 & $16 \cdot 6$ & 92 & 5 & $5 \cdot 4$ \\
\hline Black & 15 & - & - & 17 & 2 & $11 \cdot 7$ & 12 & 6 & 50 & 44 & 8 & $18 \cdot 1$ \\
\hline
\end{tabular}


(see Table 1), and this confirms other authors' findings that the IOP is the most reliable single factor in predicting future glaucoma from ocular hypertension (Armaly, 1969; Leydhecker, 1975). Thus black patients with ocular hypertension have a higher risk of developing glaucoma than white patients.

(2) In spite of the fact that in this study there were nearly twice as many white patients with ocular hypertension as blacks, $18.1 \%$ of the latter developed glaucoma compared with $5.4 \%$ in the whites.

(3) Age of presentation. The black patients with ocular hypertension were on average 12.6 years younger than their white counterparts. It is of interest that patients with primary open-angle glaucoma are also reported to be younger on average in the black population when compared with whites (Luntz, 1973b; Sarkies, 1953).

Among the white patients there is an increase in the number of patients with ocular hypertension with advancing age. This can be interpreted as a gradual increase in the intraocular pressure with age, an observation reported as far back as 1965 in the Oxford Glaucoma Survey (Luntz et al., 1965). Nevertheless, in the white group with ocular hypertension, in spite of the increase in their number with age, the percentage of those developing glaucoma gradually decreases with every age decade, suggesting that the increase in the level of IOP noted with advancing age is a physiological rather than a pathological phenomenon.

We thank Mrs Ferelyth Douglas for her assistance with the technical illustrations.

\section{References}

Armaly, M. F. (1969). Ocular pressure and visual fields. Archives of Ophthalmology, 81, 25-40.

Clarke, E. E. (1973). A comparative analysis of the age distribution and types of primary glaucoma among populations of African and Caucasian origin. Annals of Ophthalmology, 5, 1055-1071.

David, R., Livingston, D., and Luntz, M. H. (1977). Ocular hypertension-A long-term follow-up of treated and untreated patients. British Journal of Ophthalmology, 61, 668-674.

Kitazawa, Y., Horie, T., Aoki, S., Susuki, M., and Nishioka, K. (1977). Untreated ocular hypertension-A long term propspective study. Archives of Ophthalmology, 95, 1180-1184.

Leydhecker, W. (1975). Tension tolerance. In International Glaucoma Symposium, Albi, 1974, pp. 193-204. Edited by R. Etienne. Diffusion Générale de Librarie: Marseille.

Luntz, M. H., Sevel, D., and Lloyd, J. P. F. (1965). The Oxford Glaucoma Survey-Statistical analysis of the results. British Journal of Ophthalmology, 49, 128-136.

Luntz, M. H. (1972). Glaucoma and ocular hypertension. South African Medical Journal, 46, 243-245.

Luntz, M. H. (1973a). Primary angle-closure glaucoma in urbanised South African caucasoid and negroid communities. British Journal of Ophthalmology, 57, 445-456.

Luntz, M. H. (1973b). Primary open-angle glaucoma in urban negro and caucasian South African communities. South African Archives of Ophthalmology, 1, 131-140.

Mann, I. (1972). Causes and Prevention of Blindness, pp. 4043. Edited by I. C. Michaelson and E. R. Berman. Academic Press: London.

Monteiro de Gandt, D., and Maertens, K. (1973). Results of an enquiry on glaucoma simplex among black patients in the Republic of Zaire. Annalles d' Oculistique, 206, 393-399.

Neumann, E., and Zauberman, H. (1965). Glaucoma survey in Liberia. American Journal of Ophthalmology, 59, 8-12.

Sarkies, J. (1953). Primary glaucoma amongst Gold Coast Africans. British Journal of Ophthalmology, 37, 615-620.

Walker, W. M. (1974). Ocular hypertension. Follow-up of 109 cases from 1963 to 1974. Transactions of the Ophthalmological Societies of the United Kingdom, 94, 525-534. 